\title{
RESEARCH
}

Open Access

\section{Understanding and use of food labeling systems among Whites and Latinos in the United States and among Mexicans: Results from the International Food Policy Study, 2017}

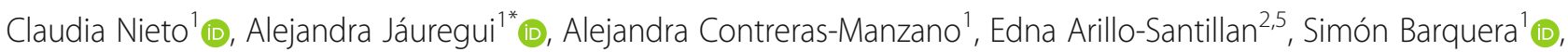
Christine M. White ${ }^{3} \mathbb{D}$, David Hammond ${ }^{3}$ (D) and James F. Thrasher ${ }^{2,4}$

\begin{abstract}
Background: Obesity and chronic diseases could be prevented through improved diet. Most governments require at least one type of food labeling system on packaged foods to communicate nutrition information and promote healthy eating. This study evaluated adult consumer understanding and use of nutrition labeling systems in the US and Mexico, the most obese countries in the world.

Methods: Adults from online consumer panels in the US (Whites $n=2959$; Latinos $n=667)$ and in Mexico $(n=3533)$ were shown five food labeling systems: 1. Nutrition Facts Table (NFT) that shows nutrients of concern per serving; 2 . Guideline Daily Amounts (GDA) that shows levels of nutrients of concern; 3. Multiple Traffic-Light (MTL) that color codes each GDA nutrient (green = healthy; yellow = moderately unhealthy; red = unhealthy); 4 . Health Star Rating System (HSR) that rates foods on a single dimension of healthiness; 5. Warning Label (WL) with a stop sign for nutrients present in unhealthy levels. Participants rated each label on understanding ("easy"/"very easy to understand" vs "difficult"/"very difficult to understand"), and, for NFTs and GDAs, frequency of use ("sometimes"/"often" vs "never"). Mixed logistic models regressed understanding and frequency of use on indicators of labeling systems (NFT = ref), testing for interactions by ethnicity (US Latinos, US Whites, Mexicans), while controlling for sociodemographic and obesity-related factors.
\end{abstract}

Results: Compared to the NFT, participants reported greater understanding of the $\mathrm{WL}(\mathrm{OR}=4.8 ; 95 \% \mathrm{Cl}=4.4-5.3)$ and lower understanding of the HSR $(O R=0.34,95 \% \mathrm{Cl}=0.31-0.37)$ and the MTL $(\mathrm{OR}=0.56,95 \% \mathrm{Cl}=0.52-0.61)$, with similar patterns across ethnic subgroups. Participants used GDAs less often than NFTs (OR $=0.48 ; 95 \% \mathrm{Cl}=0.41-0.55)$, with the greatest difference among US Whites $(\mathrm{OR}=0.10 ; 95 \% \mathrm{Cl}=0.07-0.14)$.

Conclusions: Understanding and use of the GDA was similar to that of the NFT. Whites, Latinos, and Mexicans consistently reported the best understanding for WLs, a FOPL that highlights unhealthfulness of a product. Therefore, a FOPL summary indicator, such as WLs, may be more effective in both the US and Mexico for guiding consumers towards informed food choices.

Keywords: Food labelling, White, Latinos, Mexicans, Ethnicity

\footnotetext{
* Correspondence: alejandra.jauregui@insp.mx

${ }^{1}$ Nutrition and Health Research Center, Mexican National Institute of Public Health, Av. Universidad 655 Col, Santa María Ahuacatitlán, 62100 Cuernavaca, Mexico

Full list of author information is available at the end of the article
}

(c) The Author(s). 2019 Open Access This article is distributed under the terms of the Creative Commons Attribution 4.0 International License (http://creativecommons.org/licenses/by/4.0/), which permits unrestricted use, distribution, and reproduction in any medium, provided you give appropriate credit to the original author(s) and the source, provide a link to the Creative Commons license, and indicate if changes were made. The Creative Commons Public Domain Dedication waiver (http://creativecommons.org/publicdomain/zero/1.0/) applies to the data made available in this article, unless otherwise stated. 


\section{Introduction}

The highest rates of obesity in the world are in Mexico and the United States (US) [1, 2], where 72.5\% [3] and $71.6 \%$ [4] of adults $\geq 20$ years old, respectively, are overweight or obese. Diabetes is also high in both countries at $9.4 \%$ [3, 5], along with other chronic diseases that could be prevented through improved diet. Most governments require at least one type of food labeling system on packaged foods to communicate nutrition information and promote healthy eating.

The National Health and Nutrition Examination Survey (NHANES) data has shown that $61.6 \%$ of Americans reported using a Nutrition Facts Table (NFT) [6], with a slightly lower percentage of use among US Latinos (60\%) [7]. In contrast, only $41.5 \%$ of Mexicans reported reading the NFT [8]. In minority groups, like Latinos in the US, NFT comprehension is reported to be difficult compared to their white counterparts $[9,10]$.

The NFT is the oldest labeling system implemented on pre-packaged foods to inform consumers about nutrition content. The display of NFTs on packaged foods is mandatory in the US and Mexico, and is required by the National Labeling Act of 1990 and the Official Mexican Norm 051 (NOM-051), respectively. NFTs are displayed on the back or side of the package and provide information about the nutrition content per portion $[8$, $11,12]$. One limitation of NFTs is that serving sizes often differ across brands and products; studies suggest that consistent serving sizes would facilitate compare nutrient content of similar products [13]. Consumers also have difficulty using NFTs to understand if a food is 'high' or 'low' in a nutrient [14]. Perhaps most importantly, there are persistent disparities in the use and understanding of NFTs among consumers with lower education and income $[15,16]$.

To overcome limitations of NFTs, a number of Frontof-Package Labeling (FOPL) systems have been proposed and, in some countries, adopted to better communicate nutrition information to consumers [15, 17]. FOPLs provide summary information on energy and key nutrients, such as sugar, sodium, and saturated fat $[18,19]$, to facilitate healthy food choices [15, 17]. Many food-labeling systems have been proposed, including the FOPLs discussed below, yet there is no agreement on which is most effective.

Warning Labels (WL) are displayed on the front of packages for energy and nutrients considered to be present in unhealthy levels (see Fig. 1). Products with WLs

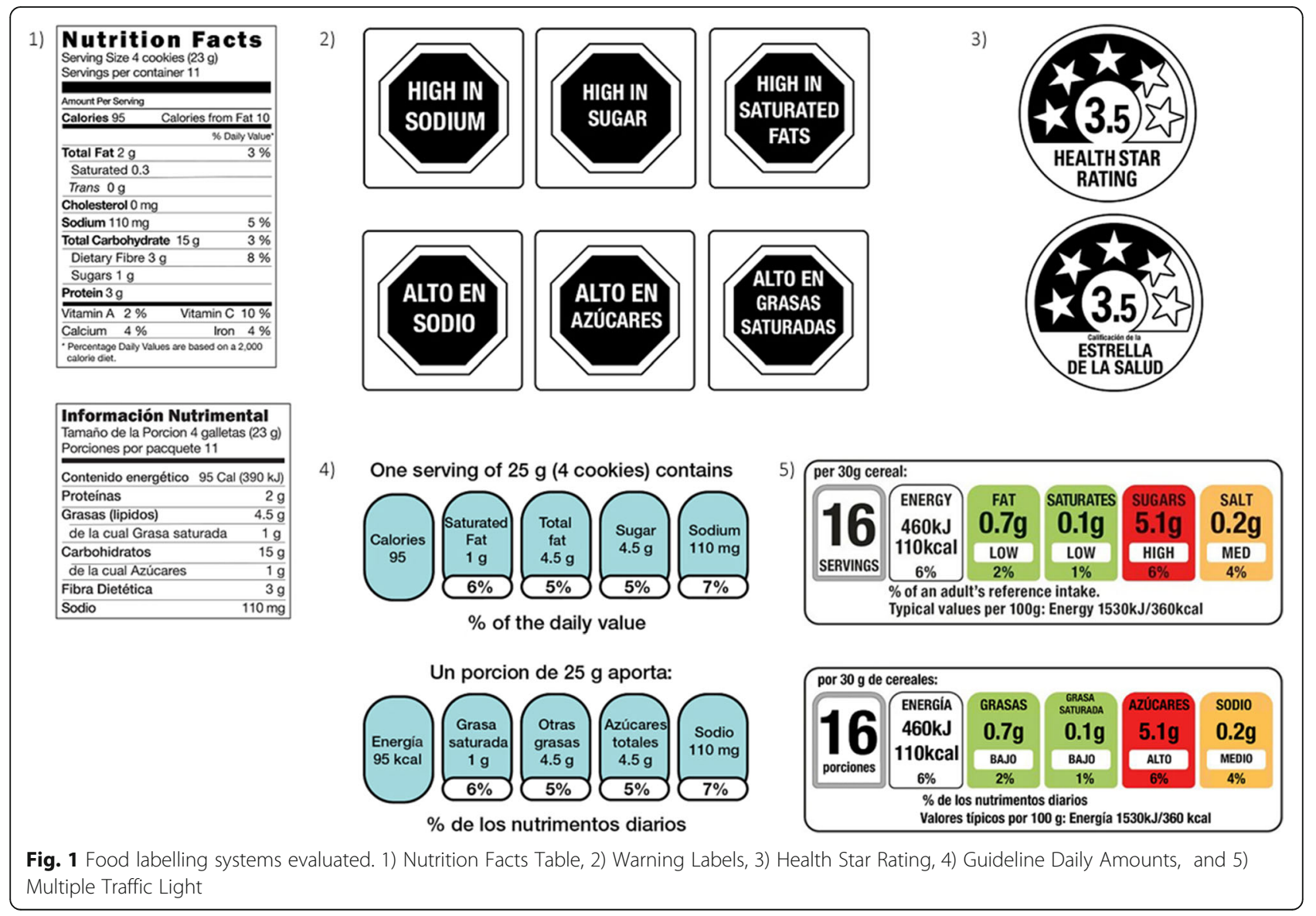


are perceived as less healthful than those with numerical FOPL systems [20, 21]. The World Health Organization has recognized that interpretive FOPL, like WLs, can help create healthier food environments because they are more easily understood by consumers at all levels of literacy and also indirectly motivate companies to put healthier products on the market [22]. Furthermore, the Pan American Health Organization indicated that WLs should be used as a tool in the design and implementation of various regulatory strategies related to the prevention and control of overweight and obesity [23]. Chile, Israel, Peru, and Uruguay recently adopted WLs as a nutrition policy tool; WLs are also under consideration in Brazil, Canada, and Mexico.

One FOPL approach favored by industry is the Guideline Daily Amounts (GDA), which shows energy and the percentage of key nutrients of concern (saturated fat, other fat, sugar and sodium) on the front of the package (see Fig. 1). GDAs have been mandatory on the front of packaged foods in Mexico since 2014. In the US, industry voluntarily uses a similar system called Facts Up Front [24], for many products. US consumers report better understanding of nutrition information presented in the GDA format than in NFTs [25]. However, US consumers show evidence of greater nutrition knowledge when using other systems (e.g., traffic light) compared to the GDA [26]. Furthermore, Mexicans show evidence of low understanding of GDA formatted information [8, 27].

The Health Star Rating (HSR) synthesizes all nutrient information into a single dimension of healthiness. The HSR was voluntarily implemented by the food industry in 2014 in Australia and New Zealand. Products receive ratings from half a star up to 5 stars, depending on the overall healthiness of the product [28]. Studies suggest that the HSR can be more effective at directing consumers towards healthier choices compared to the GDA [29].

Finally, the Multiple Traffic Light (MTL) color codes each nutrient in order to quickly communicate whether the product contains relatively low (green), average (yellow) or high (red) levels of potentially harmful nutrients [20]. Consumers using the MTL have been shown to have more accurate reports of calories per serving compared to the GDA, HSR and the single traffic light [30]. Additionally, MTLs have high acceptability among Europeans [31, 32].

This study assessed labeling systems currently used by the food industry in the US and Mexico, as well as other systems adopted by other countries. The objective was to compare adult consumers' understanding and use of five food labeling systems (NFT, WL, GDA, HSR, and MTL; see Fig. 1). Our approach is oriented by the framework of consumer decision-making proposed by Grunert, in which awareness is a necessary precursor to understanding food labels. Once labeling is understood, it may influence food choices [33]. We compared US Whites, US Latinos, and Mexicans, partly because Latinos are the largest minority group in the US [34] and the majority are of Mexican heritage [35]. Furthermore, US Latinos have disproportionately high rates of obesity and lower health literacy than Whites [36-38]. Furthermore, comparisons with Mexican consumers allowed assessment of mandated GDAs in Mexico relative to the voluntary use of FOPLs in the US.

\section{Methods}

We analyzed cross-sectional survey data from the US and Mexico administrations of the 2017 International Food Policy Study. The sample included 7159 participants aged 18 to 64 who completed an online survey in December 2017. Participants were recruited through the Nielsen Consumer Insights Global Panel and their partners. In US, participants self-reported their ethnicity. We used data from participants in the US who considered themselves 'White' or 'Hispanic or Latino'; and all participants in Mexico. The Nielsen panels were originally recruited using both probability and non-probability sampling methods in each country. For the current project, Nielsen targeted recruitment, so that the percentage of participants in each age group would be similar to the general population for each country. Latino respondents were over-sampled in the US $(n=667)$, to facilitate comparisons between US Whites $(n=2959)$ and Mexicans $(n=3533)$. Respondents provided consent prior to completing the survey. Participants received remuneration in accordance with their panel's usual incentive structure (e.g., points-based or monetary rewards, chances to win prizes). Post-stratification weights were constructed separately for each country to weight the sample so that it was similar to known sex, age, and region distributions in the general population. Surveys were conducted in Spanish in Mexico, and US participants could choose to answer either an English- or Spanish-language survey. Native and bilingual Spanish speakers on the research team reviewed the Spanish translations independently. The average time to complete the survey in US and Mexico was $35.7 \mathrm{~min}$. The study was reviewed by and received ethics clearance through a University of Waterloo Research Ethics Committee (ORE\# 21460). A full description of the study methods can be found in the International Food Policy Study: Technical Report Wave 1 (2017) at www.foodpolicystudy.com/methods.

\section{Food labeling systems evaluated}

Participants were asked to evaluate five different food labeling systems: 1) NFT, 2) WL, 3) GDA, 4) HSR, and 5) MTL (Fig. 1). Participants were shown an image of each labelling system, one at a time, and asked to answer two questions about each label before proceeding to the next 
label: 1) how easy or difficult the information was to understand (responses re-coded to 'easy/very easy to understand' vs 'neither easy nor difficult' or 'difficult/ very difficult to understand'), and 2) how often they used that type of label when choosing food to purchase (responses recoded to 'often/sometimes' vs 'never'). The label images were shown on screen with the question (one question and image per screen). Label images were presented isolated from other images rather than being part of a food package. The researchers did not give any explanation to interpret or assess the labeling systems shown.

\section{Covariates}

Covariates included socio-demographic characteristics and other variables relevant to food choices, including sex (male or female), age group (18 to 33,34 to 49 , or 50 to 64 years old), education (high school or lower, technical studies, or bachelor's degree or higher) and survey language (English or Spanish). Income adequacy was assessed with the question 'Thinking about your total monthly income, how difficult or easy is it for you to make ends meet?', with responses collapsed into difficult, neither easy nor difficult, or easy. Occupation was classified as 'full-time worker or full-time student', 'parttime worker and/or part-time student' or 'unemployed'.

Body Mass Index (BMI) measurement followed World Health Organization criteria [39], wherein self-reported height and weight were used to classify participants as underweight $\left(18.5 \mathrm{~kg} / \mathrm{m}^{2}\right)$, normal weight (18.5 to $24.9 \mathrm{~kg} /$ $\left.\mathrm{m}^{2}\right)$, overweight $\left(25.0\right.$ to $\left.29.9 \mathrm{~kg} / \mathrm{m}^{2}\right)$, or obese $(>30 \mathrm{~kg} /$ $\mathrm{m}^{2}$ ). Self-reported nutrition knowledge was assessed with the question 'How would you rate your nutrition knowledge?' with responses collapsed into not knowledgeable, or somewhat knowledgeable / knowledgeable. Daily calorie count was queried by asking 'Do you count calories you consume each day?' with responses including 'never', 'sometimes', and 'most of the time'. Household responsibility for food shopping was assessed by asking whether the participant did most of the food shopping in their household ('yes', 'no', or 'share equally with others').

\section{Statistical analysis}

Pearson chi square tests were used to evaluate sample differences by ethnicity (US Whites, US Latinos, and Mexicans). Prevalence and 95\% confidence intervals were estimated for understanding and use of each food labeling system, both overall and by ethnicity.

Crude and adjusted mixed-effects logistic models were estimated by regressing understanding of food labels $(0=$ difficult $/$ very difficult $/$ neither easy nor difficult, $1=$ easy/very easy) on each type of labeling system $(\mathrm{NFT}=$ Reference group). This approach was also used in models where label use $(0=$ never, $1=$ often/sometimes $)$ was the outcome and labeling systems currently in use in both countries were the independent variable (i.e., GDA and NFT) (NFT = Reference group). Adjusted models included all covariates described in methods. Since our initial models indicated that significant differences in label understanding existed across ethnicities, models were estimated both for the entire sample and stratified by ethnicity. We used the F-test to test for significance $(p<0.05)$. Model fit was tested with goodness of fit of the model. All analysis were performed in STATA, version 14 (StataCorp, L.P., College Station, TX).

\section{Results}

A total of 7159 adults were included in the present study. US participants who were neither White nor Latino were excluded from the analysis $(n=118)$. Participants with missing data for the covariates and dependent variables were also excluded from the analysis $(n=1345)$. In the total sample $(n=7159), 39 \%$ [95\% CI: 38.36-41.09] were US whites, 10\% [95\% CI: 9.46-11.22] were US Latinos, and 50\% [95\% CI: 48.57-51.35] were Mexicans (Table 1). Across ethnicities, US white participants had the highest proportion of older adults (41.8\%, [95\%CI: 39.64-43.94]), self-reported obesity (26.4\%, [95\% CI: 24.54-28.42]), participants reporting it was easy to make the ends meet (53.3\%, [95\% CI: 51.02-55.46]) and being a full-time worker or student $(61.1 \%$, [95\% CI: 58.92-63.22]) $(p<$ 0.001 for all). Mexican participants had higher education level (bachelor's degree or higher) (71.8\%, [95\% CI: 70.0873.50]), reported that they were somewhat knowledgeable about nutrition (55.1\%, [95\% CI: 53.21-57.05]) and reported that they never counted calories $(70.8 \%$, [95\% CI: 69.06-72.58]) ( $p<0.05$ for all). A higher proportion of US Latino participants reported doing most of the food shopping for their household (75.3\%, [95\% CI: 71.17-79.07]) $(p<0.05)$. The majority of US Latinos $(67.4 \%$, [95\% CI: 63.14-71.46]) answered the survey in Spanish.

Figure 2 presents the prevalence of reported understanding of food labeling systems among Whites, Latinos, and Mexicans. Across ethnicities, Whites reported the highest level of understanding (87, 95\% CI: 85.9188) for WL, and reported lowest understanding of the HSR (34, 95\% CI: 32.30-36.63) and the MTL (47, 95\% CI: 45.10-49.57) labels. Latinos and Mexicans also reported high understanding for WL (82 and $84 \%$, respectively).

Figure 3 shows the use of the GDA and the NFT. US Latinos reported the highest levels of use for the GDA and NFT labeling systems (GDA: 91, 95\% CI: 88-94; NFT: 94, 95\% CI: 92-96\%). While 31\% reported using GDAs "sometimes" and 60\% reported using them "often". Almost all Whites reported using the NFT (98, 95\% CI: 97-98\%): $28 \%$ reported using the NFT 
Table 1 Socio-demographic characteristics of White, Latino and Mexican population who participated in the IFPS $(n=7159)^{*}$

\begin{tabular}{|c|c|c|c|c|}
\hline & White $(n=2959)$ & Latino $(n=667)$ & Mexican $(n=3533)$ & $P$ value ${ }^{a}$ \\
\hline & $\%[95 \% \mathrm{Cl}]$ & $\%[95 \% \mathrm{Cl}]$ & $\%[95 \% \mathrm{Cl}]$ & \\
\hline \multicolumn{5}{|l|}{ Sex } \\
\hline Female & 49.88 [47.65-52.10] & 49.51 [44.99-54.03] & 51.42 [49.49-53.33] & \multirow[t]{2}{*}{$p=0.5313$} \\
\hline Male & 50.12 [47.89-52.34] & 50.49 [45.96-55.00] & 48.58 [46.66-50.50] & \\
\hline \multicolumn{5}{|l|}{ Age group } \\
\hline $18-33$ & 28.62 [26.74-30.57] & 42.15 [37.82-46.59] & $42.74[40.92-44.57]$ & \multirow[t]{3}{*}{$p<0.001$} \\
\hline $34-49$ & 29.60 [27.41-31.88] & 45.96 [41.42-50.55] & 35.53 [33.72-37.38] & \\
\hline $50-64$ & 41.78 [39.64-43.94] & 11.89 [9.46-14.85] & 21.72 [19.82-23.74] & \\
\hline \multicolumn{5}{|l|}{ Survey language } \\
\hline English & 100 & 32.55 [28.53-36.85] & 0 & \multirow[t]{2}{*}{$p<0.001$} \\
\hline Spanish & 0 & $67.45[63.14-71.46]$ & 100 & \\
\hline \multicolumn{5}{|l|}{ Education level } \\
\hline High school or lower & 18.48 [16.79-20.30] & 24.34 [20.73-28.34] & 15.68 [14.39-17.05] & \multirow[t]{3}{*}{$p<0.001$} \\
\hline Technical studies & 20.02 [18.28-21.87] & 20.61 [17.07-24.65] & 12.49 [11.24-13.85] & \\
\hline Bachelor's degree or higher & 61.50 [59.29-63.64] & $55.05[50.50-59.51]$ & 71.83 [70.08-73.50] & \\
\hline \multicolumn{5}{|l|}{ Income adequacy } \\
\hline Difficult & 16.46 [14.86-18.18] & 29.84 [25.80-34.21] & 41.55 [39.64-43.47] & \multirow[t]{3}{*}{$p<0.001$} \\
\hline Neither easy nor difficult & 30.29 [28.28-32.37] & 36.87 [32.59-41.36] & 38.32 [36.46-40.20] & \\
\hline Easy & $53.25[51.02-55.46]$ & 33.29 [29.23-37.60] & 20.14 [18.66-21.69] & \\
\hline \multicolumn{5}{|l|}{ Occupation } \\
\hline Worker or student & 61.10 [58.92-63.22] & 54.18 [49.65-58.63] & 55.50 [53.57-57.40] & \multirow[t]{3}{*}{$p<0.001$} \\
\hline Unemployed & 24.45 [22.63-26.35] & 20.31 [17.02-24.04] & 14.41 [13.08-15.85] & \\
\hline Part time student and/or pt-worker & $14.45[12.95-16.08]$ & $25.51[21.75-29.66]$ & 30.09 [28.37-31.86] & \\
\hline \multicolumn{5}{|l|}{$\mathrm{BM} \mathrm{I}^{\mathrm{b}}$} \\
\hline Normal weight & $38.02[35.89-40.18]$ & $39.43[35.10-43.93]$ & $44.72[42.82-46.64]$ & \multirow[t]{3}{*}{$p<0.001$} \\
\hline Overweight & $35.54[33.40-37.73]$ & 37.38 [33.10-41.85] & $36.27[34.41-38.15]$ & \\
\hline Obesity & $26.44[24.54-28.42]$ & 23.19 [19.54-27.27] & 19.01 [17.53-20.57] & \\
\hline \multicolumn{5}{|l|}{ Self-report of nutrition knowledge } \\
\hline Not knowledgeable & 26.87 [24.89-28.94] & 27.41 [23.57-31.60] & $29.92[28.22-31.67]$ & \multirow[t]{3}{*}{$p<0.001$} \\
\hline Somewhat knowledgeable & $43.45[41.25-45.65]$ & $51.44[46.91-55.95]$ & $55.14[53.21-57.05]$ & \\
\hline Knowledgeable & $29.68[27.71-31.73]$ & $21.15[17.65-25.11]$ & 14.94 [13.52-16.47] & \\
\hline \multicolumn{5}{|l|}{ Daily calorie count } \\
\hline Never & $62.03[59.85-64.16]$ & $56.57[52.03-60.99]$ & $70.86[69.06-72.58]$ & \multirow[t]{3}{*}{$p<0.001$} \\
\hline Sometimes & $31.16[29.14-33.24]$ & $36.61[32.35-41.08]$ & 25.57 [23.93-27.28] & \\
\hline Most of the time & $6.81[5.76-8.02]$ & $6.82[4.92-9.37]$ & $3.57[2.85-4.44]$ & \\
\hline \multicolumn{5}{|l|}{ Food shopping in your household } \\
\hline Yes & $66.44[64.26-68.55]$ & 75.34 [71.17-79.07] & 67.97 [66.19-69.68] & \multirow[t]{3}{*}{$p<0.001$} \\
\hline No & $10.94[9.45-12.61]$ & $8.16[5.94-11.11]$ & $8.66[7.71-9.70]$ & \\
\hline Share & 22.62 [20.83-24.50] & 16.49 [13.37-20.16] & 23.38 [21.83-24.99] & \\
\hline
\end{tabular}

95\% Cl $=95 \%$ Confidence Intervals

*Data were weighted using survey weights

${ }^{a}$ Pearson $\mathrm{X} 2$ tests were calculated to determine differences by socio-demographic characteristics and ethnicity

${ }^{b}$ Body Mass Index (BMI) classification: normal weight (18.5 to $\left.24.9 \mathrm{~kg} / \mathrm{m} 2\right)$, overweight ( 25.0 to $\left.29.9 \mathrm{~kg} / \mathrm{m} 2\right)$, and obesity (>30 kg/m2) 


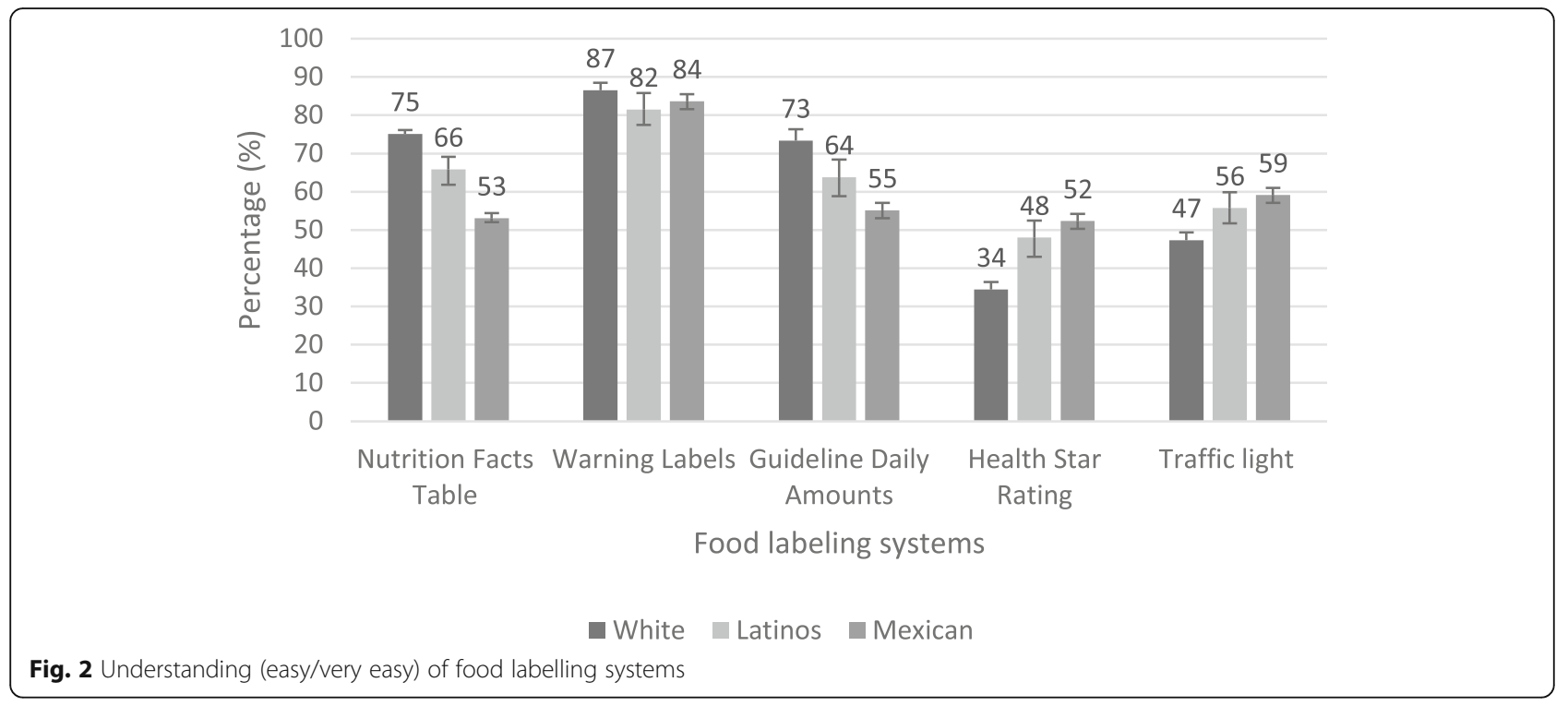

"sometimes", while 70\% reported using the NTF "often". A lower percentage of Mexicans reported using GDAs (84, 95\% CI: 82-85) and NFTs (84, 95\% CI: 83-86\%).

Across the total sample, the adjusted model for label understanding (Table 2) indicated that participants were 4.82 (95\%CI: 4.39-5.30) times more likely to report understanding the WL compared to the NFT. In contrast, reported understanding of the HSR $(\mathrm{OR}=0.34,95 \% \mathrm{CI}$ : $0.31-0.37)$ and the MTL (OR $=0.56,95 \%$ CI: 0.52-0.61) were lower compared to the NFT.

The understanding of FOPL systems relative to NFT differed by ethnicity $(p<0.05$ for the interaction term Ethnicity $\mathrm{x}$ labelling system, data not shown). Compared to Latinos, Mexicans were more likely to report understanding the WL $(\mathrm{OR}=2.15,95 \%$ CI $1.54-3.01)$, HSR
$(\mathrm{OR}=2.44,95 \% \mathrm{CI}: 1.80-3.32)$ and $\mathrm{MTL}(\mathrm{OR}=2.39$, 95\% CI $=1.79-3.17)$ than the NFT. Compared to Latinos, Whites had lower odds for understanding the HSR and MTL (HSR OR $=0.23,95 \% \mathrm{CI}=0.17-0.32$; $\mathrm{MTL}$ $\mathrm{OR}=0.34,95 \% \mathrm{CI}=0.25-0.46$ ).

When stratified by ethnicity (Table 2), participants were more likely to report understanding the WL compared to the NFT $(p<0.05)$ across all ethnicities (Whites $\mathrm{OR}=2.90,95 \% \mathrm{CI}=2.49-3.38 ;$ Latinos $\mathrm{OR}=4.07,95 \%$ $\mathrm{CI}=2.92-5.68$; Mexican $\mathrm{OR}=7.95,95 \% \mathrm{CI}=6.89-9.16$ ), and all ethnicities were less likely to report understanding the GDAs compared to the NFT $(p<0.05)$. The MTL and HSR had a lower rating of understanding among Whites $(\mathrm{MTL}=0.19,95 \% \mathrm{CI}: 0.17-0.22$; HSR $=$ $0.09,95 \%$ CI: $0.08-0.11)$ and Latinos $(\mathrm{MTL}=0.52,95 \%$

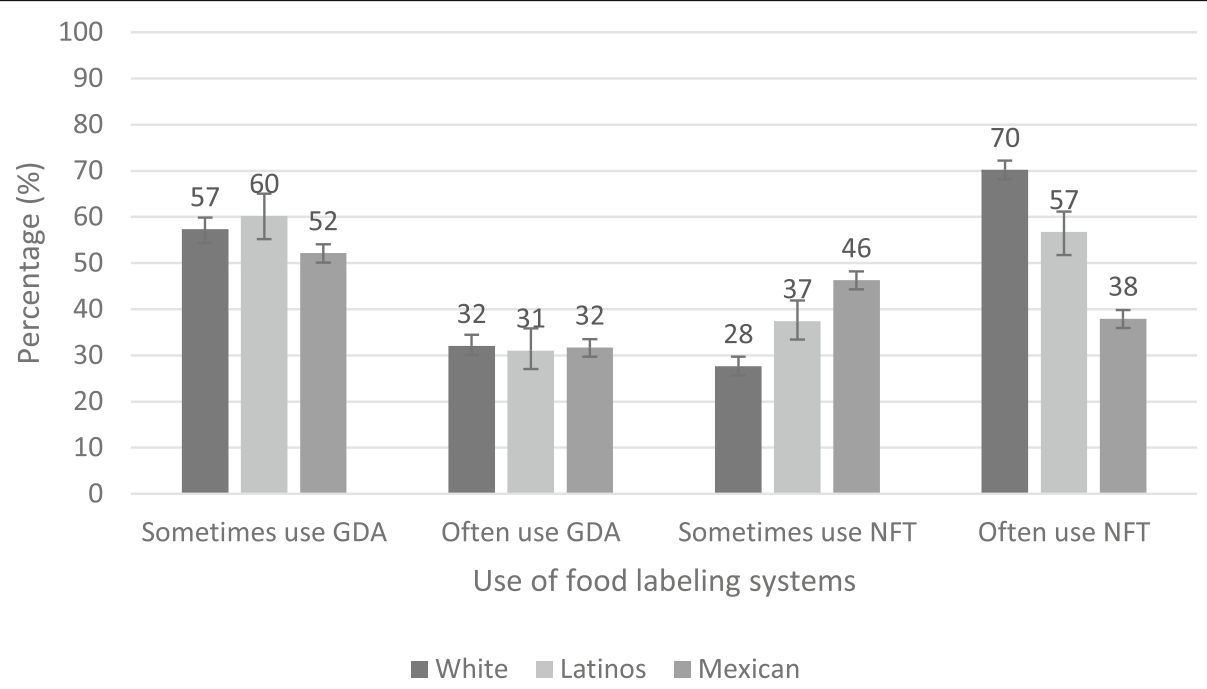

Fig. 3 Use (sometimes/often) of the Guideline Daily Amounts and Nutrition Facts Table 
Table 2 Odds ratios for considering it easy or very easy to understand different food labelling systems*

\begin{tabular}{|c|c|c|c|c|c|c|c|c|}
\hline & \multicolumn{2}{|c|}{ Total sample $(N=35,618)$} & \multicolumn{2}{|c|}{ White $(n=14,692)$} & \multicolumn{2}{|c|}{ Latino $(n=3316)$} & \multicolumn{2}{|c|}{ Mexican $(n=17,610)$} \\
\hline & $\%$ & OR $[95 \% \mathrm{Cl}]$ & $\%$ & OR $[95 \% \mathrm{Cl}]$ & $\%$ & OR $[95 \% \mathrm{Cl}]$ & $\%$ & $\mathrm{OR}[95 \% \mathrm{Cl}]$ \\
\hline \multicolumn{9}{|l|}{ Labelling Scheme (Ref. NFT) } \\
\hline Warning Labels & 85 & $4.82[4.39-5.30] * * *$ & 87 & $2.90[2.49-3.38]^{* * *}$ & 82 & $4.07[2.92-5.68]^{* * *}$ & 84 & $7.95[6.89-9.16]^{* * *}$ \\
\hline Guideline Daily Amounts & 63 & 1.02 [0.95-1.09] & 73 & $0.94[0.83-1.07$ & 64 & $1.04[0.80-1.37]$ & 55 & 1.08 [0.98-1.19] \\
\hline Health Stars Rating & 45 & $0.34[0.31-0.37]^{* * *}$ & 34 & $0.09[0.08-0.11]^{* * *}$ & 48 & $0.35[0.25-0.47]^{* * *}$ & 52 & $0.92[0.81-1.04]$ \\
\hline Multiple Traffic Light & 54 & $0.56[0.52-0.61]^{* * *}$ & 47 & $0.19[0.17-0.22]^{* * *}$ & 56 & $0.52[0.39-0.69]^{* * *}$ & 59 & $1.31[1.17-1.45]^{* * *}$ \\
\hline \multicolumn{9}{|l|}{ Ethnicity (Ref. Latino) } \\
\hline White & 63 & $0.89[0.75-1.05]$ & - & - & - & - & - & - \\
\hline Mexican & 61 & $0.96[0.82-1.13]$ & - & - & - & - & - & - \\
\hline \multicolumn{9}{|l|}{ Sex (Ref. Man) } \\
\hline Woman & 63 & $1.10[1.01-1.20]^{*}$ & 65 & $1.27[1.11-1.46]^{* * *}$ & 65 & 1.34 [0.93-1.93] & 61 & $0.97[0.86-1.11]$ \\
\hline Age (years) & & $1.00[1.00-1.00]$ & & $1.00[1.00-1.01]$ & & $1.00[0.98-1.01]$ & & $1.00[0.99-1.00]$ \\
\hline \multicolumn{9}{|l|}{ Survey language (Ref. English) } \\
\hline Spanish & 56 & $1.02[0.75-1.38]$ & - & - & 67 & $1.18[0.83-1.66]$ & - & - \\
\hline \multicolumn{9}{|c|}{ Education (Ref. High-school or lower) } \\
\hline Technical studies & 64 & $1.08[0.93-1.25]$ & 65 & $0.97[0.78-1.22]$ & 68 & $1.71[1.01-2.90]^{*}$ & 61 & $1.07[0.85-1.36]$ \\
\hline Bachelor's degree or higher & 62 & $0.91[0.81-1.02]$ & 63 & $0.85[0.71-1.03]$ & 63 & $1.08[0.71-1.64]$ & 61 & $0.93[0.78-1.11]$ \\
\hline \multicolumn{9}{|l|}{ Income adequacy (Ref. Difficult) } \\
\hline Neither easy nor difficult & 60 & $1.04[0.94-1.16]$ & 60 & $0.82[0.68-1.00]^{*}$ & 60 & $0.89[0.60-1.34]$ & 61 & $1.15[1.00-1.31]^{*}$ \\
\hline Easy & 66 & $1.40[1.25-1.56]^{* * *}$ & 65 & $1.18[0.98-1.41]$ & 65 & $1.32[0.87-2.00]$ & 67 & $1.53[1.28-1.82]^{* * *}$ \\
\hline \multicolumn{9}{|l|}{ Occupation (Ref. Unemployed) } \\
\hline Part time worker or student & 62 & $0.92[0.82-1.03]$ & 63 & $0.88[0.75-1.04]$ & 56 & $0.74[0.47-1.14]$ & 62 & $0.97[0.80-1.18]$ \\
\hline Worker or student & 62 & $0.96[0.87-1.07]$ & 64 & $0.93[0.77-1.11]$ & 66 & $0.52[0.34-0.79]^{* * *}$ & 61 & $1.08[0.94-1.25]$ \\
\hline \multicolumn{9}{|l|}{ BMI (Ref. Normal weight) } \\
\hline Overweight & 62 & $0.92[0.83-1.01]$ & 64 & $1.00[0.86-1.16]$ & 59 & $0.74[0.50-1.10]$ & 60 & $0.92[0.80-1.06]$ \\
\hline Obesity & 61 & $0.94[0.84-1.05]$ & 64 & $1.05[0.89-1.24]$ & 64 & $1.11[0.72-1.71]$ & 58 & $0.83[0.70-0.98]^{*}$ \\
\hline \multicolumn{9}{|c|}{ Nutrition Knowledge (Ref. Not knowledgeable) } \\
\hline Somewhat Knowledgeable & 62 & $1.41[1.28-1.56]^{* * *}$ & 62 & $1.23[1.05-1.43]^{* *}$ & 62 & $1.70[1.15-2.51]^{* *}$ & 62 & $1.51[1.31-1.75]^{* * *}$ \\
\hline Knowledgeable & 69 & $1.97[1.75-2.22]^{* * *}$ & 73 & $1.76[1.48-2.08]^{* * *}$ & 68 & $3.19[1.99-5.14]^{* * *}$ & 73 & $2.04[1.66-2.51]^{* * *}$ \\
\hline \multicolumn{9}{|l|}{ Calorie count (Ref. Never) } \\
\hline Sometimes & 66 & $1.28[1.17-1.41]^{* * *}$ & 67 & $1.30[1.13-1.50]^{* * *}$ & 59 & $0.75[0.52-1.09]$ & 67 & $1.40[1.21-1.62]^{* * *}$ \\
\hline Most of the time & 69 & $1.51[1.25-1.81]^{* * *}$ & 69 & $1.64[1.28-2.10]^{* * *}$ & 73 & $1.14[0.60-2.18]$ & 68 & $1.49[1.06-2.10]^{*}$ \\
\hline \multicolumn{9}{|l|}{ Food shopping (Ref. Yes) } \\
\hline No & 59 & $0.90[0.78-1.04]$ & 64 & $1.03[0.83-1.29]$ & 62 & $0.84[0.44-1.58]$ & 54 & $0.82[0.66-1.01]$ \\
\hline Share & 62 & 1.03 [0.93-1.14] & 64 & 1.15 [0.99-1.34] & 63 & 0.99 [0.65-1.50] & 60 & $0.97[0.84-1.13]$ \\
\hline
\end{tabular}

OR = Odds Ratio; $95 \% \mathrm{Cl}=95 \%$ Confidence Intervals

Mixed models were adjusted for sex, age, survey language, education, income adequacy, occupation, BMI, nutrition knowledge, calorie count, and food shopping in household

Significance levels: $P$ value ${ }^{*}<0.05,{ }^{* *}<0.01,{ }^{* * *}<0.001$

*Data were weighted using survey weights

CI: $0.39-0.69$; $\mathrm{HSR}=0.35,95 \%$ CI: $0.25-0.47$ ), whereas the MTL had a better rating of understanding among Mexicans (MTL $=1.31,95 \%$ CI: $1.17-1.45)$, compared to the NFT.

Adjusted models of label use for the full sample indicated that participants were less likely $(\mathrm{OR}=0.48,95 \%$
$\mathrm{CI}=0.41-0.55)$ to report using GDAs compared to the NFT (Table 3). In the full sample, women, participants with a higher level of education, more nutrition knowledge, reporting to find it easy to make ends meet, and those who reported to count calories had a higher odds of using food labels. The use of labels differed by 
Table 3 Odds ratios for often or sometimes using the Guideline Daily Amounts*

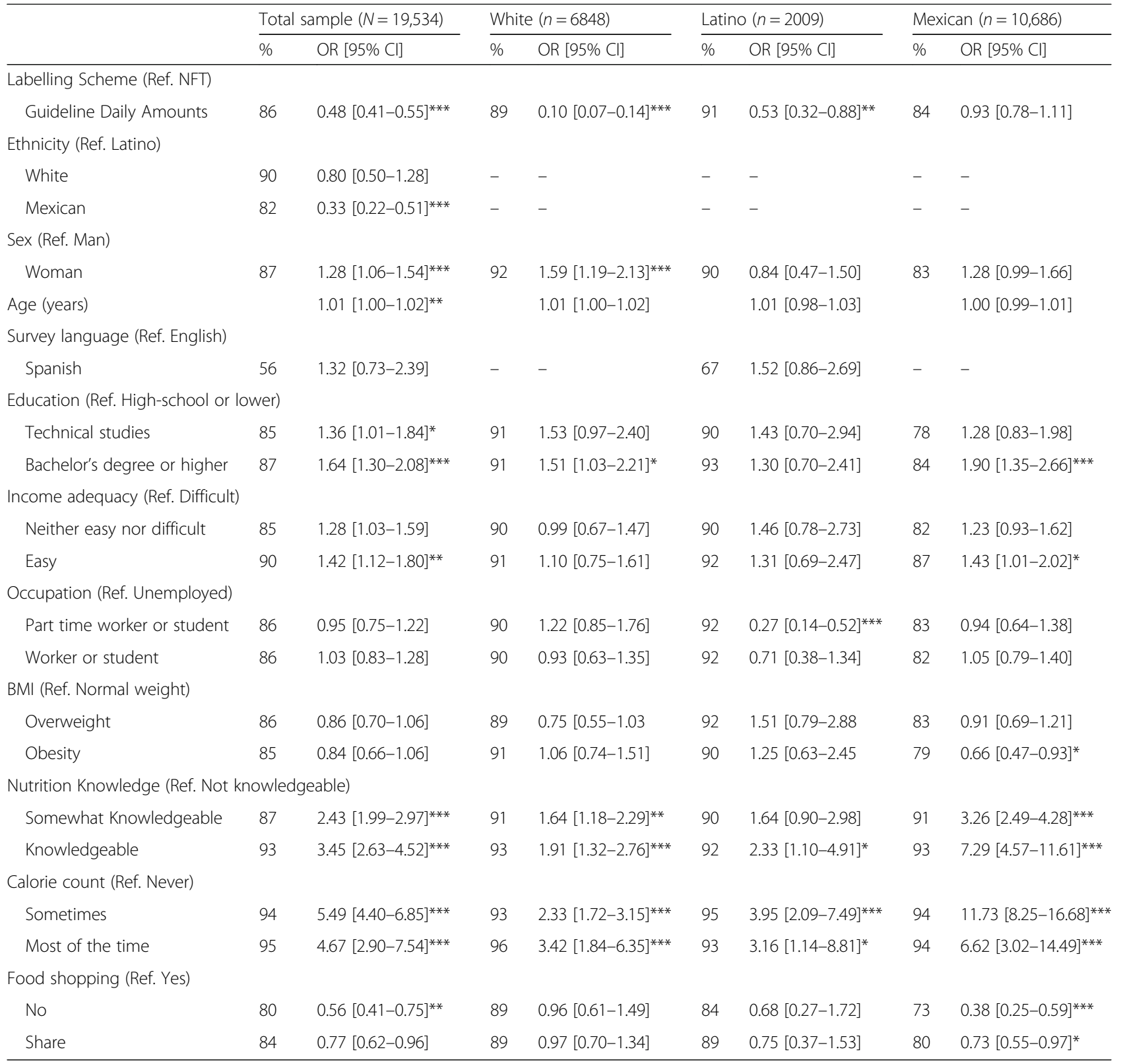

OR Odds Ratio, 95\% Cl 95\% Confidence Intervals

Mixed models were adjusted for sex, age, survey language, education, income adequacy, occupation, BMI, nutrition knowledge, calorie count, and food shopping in household

Significance levels: $P$ value $*<0.05, * *<0.01, * * * 0.001$

${ }^{*}$ Data were weighted using survey weights

ethnicity $(p<0.05$ for the interaction term Ethnicity $\mathrm{x}$ labelling system).

When stratified by ethnicity, the use of the GDA remained significant for Whites $(\mathrm{OR}=0.10,95 \% \mathrm{CI}=$ $0.07,0.14)$ and Latinos $(\mathrm{OR}=0.53,95 \% \mathrm{CI}=0.32-$ 0.88 ) only. Both ethnicities were less likely to report using the GDAs compared to the NFT. In all stratified models, women, participants with a higher level of education, more nutrition knowledge, reporting to find it easy to make ends meet, and those who reported to count calories had a higher odds of using food labels.

\section{Discussion}

Our study indicated that understanding and use of the GDA is similar to that of the NFT, suggesting that GDAs may not provide additional guidance to consumers to make informed food choices. Even in Mexico, where implementation of the GDA on the front of the 
packages was accompanied with a massive media campaign sponsored by the food industry, this labeling scheme was not more understood or used than the NFT. This is not surprising given that GDAs communicate the same nutrient numbers displayed in NFTs, with relatively little interpretative information compared to other FOPL systems. Our results also suggest differences in the understanding and use of food labeling schemes across ethnicities.

The GDA is currently displayed on the packages of processed foods in both Mexico and US [24, 40]. This non-interpretative labeling format was introduced by the food industry as their response to the need to provide simplified nutrition information for consumers [41]. However, studies in Mexico and other countries indicated that the GDA may not help consumers to make informed food purchases and does not promote healthy food choices due to difficulties understanding quantitative nutrient amounts, even among highly educated populations $[8,27,42]$. In line with these findings, in our study the self-reported understanding and use of the GDA was similar to NFTs across the three populations. Like NFTs, the GDA requires consumers to do mathematical calculations which may be a determining factor for a poor understanding [43]. Indeed, consumers demonstrate even greater deficits in understanding when consumers are asked to apply nutrient numbers featured in GDAs in functional tests, rather than simply self-report their level of understanding $[20,44]$. Additionally, the nutritional criteria used for estimating GDA are not based on international benchmarks [43]. Taken together, these findings support the growing evidence suggesting that GDA is an inadequate FOPL to promote healthy food choices among consumers.

In our study we also tested the understanding of other semi-directive (HSR and MTL) labeling formats, which in theory have better potential to guide consumers towards healthy food choices $[45,46]$. Interestingly, the reported understanding for the HSR was lower than that of the NFT among Whites and Latinos, whereas among Mexicans, the understanding of this labeling format was similar to the NFT. However, a qualitative study among Hispanic adults showed that front of package labels with star formats were not easily understood or liked [12]. Additionally, since consumers in the US and Mexico are not familiar with the HSR, this may contribute to their reported difficulty understanding the HSR.

Ecuador successfully implemented the MTL which helped consumers reduce the consumption of products with high levels of fat, sugar and salt [47]. In the present study, the MTL was also associated with lower reported understanding compared to the NFT among Latinos and Whites, but not Mexicans. This is in line with a study showing good subjective understanding for the MTL among Mexican consumers [12]. Differences in the understanding of labels by ethnicities also support the hypothesis that labels should be targeted towards specific populations [48], as cultural factors may determine the effectiveness of a label [7, 9]. Additionally, different acculturation levels between Whites and Latinos may influence the use of nutrition information [10, 49].

WLs appeared to be the most effective FOPL format for Mexicans, Latinos and Whites. Despite some differences in understanding across ethnicities, this label format consistently had the highest rating for reported understanding. The high ratings for WLs might be explained by the finding that interpretive labels that include information on product unhealthfulness tend to better support consumers to choose nutritionally favorable products [22]. Our findings are consistent with previous studies in Latin American adults showing that WLs improve consumer's ability to correctly identify products containing excessive amounts of critical nutrients, compared with the GDA system [20, 50]. Studies conducted in Brazil and Uruguay demonstrated the ease and rapidity of WL understanding at the point of sale $[20,50]$. For example, in a randomized experiment in Brazil, WLs improved understanding of excess nutrient content (27.0\% versus $8.2 \%, p<0.001$ ); and helped participants to correctly identify healthier products $(14.0 \%$ versus $6.9 \%, p<0.001)$ [50]. A study in Uruguay found that introducing WLs reduced response time when shopping compared to the GDA [20].

Overall, women had higher odds of understanding the labels than men. In prior studies, females tend to better understand and use food labels $[48,51]$ compared to men. Other research among Latino women in the US indicates that they are less acculturated than Latino men $[37,52]$, nevertheless in our Latino sample we did not find statistically significant differences by sex. We integrated a proxy measure of acculturation into our analyses by adjusting for language of survey administration; however, acculturation is a complex process and enriched measures may be needed to better understand whether lower acculturation among Latina women helps explain our counterintuitive findings [53, 54]. Our results show that Latinos with higher education levels have higher odds of understanding food labels; other international studies have also found similar results [55-59]. Whites reported a higher labeling understanding compared to Latinos. On the other hand, Latinos reported a higher use of labels. This might be explained by the Latino participant's desire to please the interviewer; some studies have documented that Latinos have a higher probability of acquiescence response bias [60].

\section{Strengths and limitations of the study}

This is the first food labeling study that compares White, Latino and Mexican populations, and as such may be of 
international interest to several countries who are looking to modify their current food labelling policies. This study is subject to a variety of limitations. First, the use of an online survey might have biased the findings in Mexico as $40 \%$ of the Mexican population does not have internet access and internet is often restricted to certain residential areas [61]. Also, the Mexico sample had higher levels of education [3], likely resulting in higher levels of understanding and use of labeling than would be found in the general population. A similar pattern was observed for education among US Whites and Latinos [62], but the education level was particularly high in the Mexico sample. However, the analysis was adjusted by education in statistical models when examining differences across the ethnic sub-groups. BMI was somewhat lower in our sample than for national estimates. This may be partially explained by the known underreporting for weight and over-reporting for height [63, 64]; however, it may also mean that our sample had healthier food patterns and therefore may have been more likely to use labels than the general population.

Additionally, the present study assessed self-reported use of labels, which is likely to over-estimate actual use [31, 65]. Label understanding was also self-reported, although subjective understanding provides a reasonable approximation on the extent to which consumers believe they have "understood" what is being communicated, and this likely reflects the effectiveness of the label [31]. Future research should use protocols that involve a more objective assessment of understanding with real food products and behavioral outcomes, such as purchasing. Finally, US Latino participants did not provide information about their specific heritage and there may be important differences in our outcomes across specific ethnic subgroups of Latinos. Still, it is likely that most of our Latino sample was of Mexican heritage, given that almost two-thirds of US Latinos are from this ethnic subgroup [34].

\section{Conclusions}

Our study found that understanding and use of the GDA was similar to that of the NFT, suggesting that this labeling format may not provide much additional guidance to consumers to make healthier food choices. Whites, Latinos, and Mexican participants consistently reported the best understanding when using WLs that highlight the unhealthfulness of a product. A FOP summary indicator, such as WLs, may be effective in both the US and Mexico for guiding consumers towards informed food choices.

\section{Abbreviations}

BMl: Body Mass Index; FOPL: Front-of-Pack Labeling; GDA: Guideline Daily Amounts; HSR: Health Star Rating; MTL: Multiple Traffic Light; NFT: Nutrition Facts Table; US: United States; WL: Warning Label

\section{Acknowledgements}

The authors would like to acknowledge Luis Zavala for his assistance running the statistical models.

\section{Authors' contributions}

$\mathrm{CN}$ performed the statistical analysis and wrote the first draft of the manuscript. ACM helped analyze and interpret data, and prepared the graphs. DH conceived, designed and executed the International Food Policy Study. AJ, SB and JT contributed to the preparation of the survey and designed the analysis of this study. AJ and JT supervised the statistical analysis. EAS, AJ, JT, CW, and DH revised the manuscript critically for intellectual content. All authors read and approved the final manuscript.

\section{Funding}

Funding for this project was provided by a Population Health Intervention Research operating grant from the Canadian Institutes of Health Research (CIHR) and the Public Health Agency of Canada. Additional funding for this project has been provided by a PHAC - CIHR Chair in Applied Public Health $(\mathrm{DH})$. The funding agency did not play any role in the design of the study, analysis and interpretation of data and in writing the manuscript.

\section{Availability of data and materials}

The datasets used and/or analyzed during the current study are available from the corresponding author on reasonable request.

\section{Ethics approval and consent to participate}

The study was reviewed by and received ethics clearance through a University of Waterloo Research Ethics Committee (ORE\# 21460). A full description of the study methods can be found in the International Food Policy Study: Technical Report - Wave 1 (2017) at www.foodpolicystudy. com/methods.

\section{Consent for publication}

Not applicable.

\section{Competing interests}

The authors declare that they have no competing interests.

\section{Author details}

${ }^{1}$ Nutrition and Health Research Center, Mexican National Institute of Public Health, Av. Universidad 655 Col, Santa María Ahuacatitlán, 62100 Cuernavaca, Mexico. ${ }^{2}$ Population Health Research Center, Mexican National Institute of Public Health, Av. Universidad 655 Col. Santa María Ahuacatitlán, 62100 Cuernavaca, Mexico. ${ }^{3}$ School of Public Health and Health Systems, University of Waterloo, 200 University Avenue West, Waterloo, ON N2L 3G1, Canada. ${ }^{4}$ Department of Health Promotion, Education \& Behavior, Arnold School of Public Health, University of South Carolina, 921 Assembly St, Columbia, SC 29208, USA. ${ }^{5}$ School of Demography, ANU College of Arts and Social Sciences, The Australian National University, 9 Fellows Road Acton ACT 260, Canberra, Australia.

Received: 27 March 2019 Accepted: 16 August 2019

Published online: 17 October 2019

References

1. Popkin BM. Is the obesity epidemic a national security issue around the globe? Curr Opin Endocrinol Diabetes Obes. 2011;18:328-31.

2. Elder JP. Mexico and the USA: the world's leaders in the obesity epidemic. Salud Publica Mex. 2013;55.

3. Shamah T, Cuevas L, Gaona E. Encuesta Nacional de Salud y Nutrición de Medio Camino 2016: Informe final de resultados; 2016.

4. National Center for Health Statistics. Health United States report 2016. Cent Dis Control. 2017; Available from: https://www.cdc.gov/nchs/data/hus/ hus16.pdf\#056\%0Ahttps://www.cdc.gov/nchs/data/hus/hus16.pdf\%23056\% OAhttps://www.cdc.gov/nchs/data/hus/hus16.pdf\%23listtables\%0Ahttps:// www.cdc.gov/nchs/data/hus/hus16.pdf\%23019.

5. Centers for Disease Control and Prevention. National Center for Chronic Disease Prevention and Health Promotion. National Diabetes Statistics Report, 2017: Estimates of Diabetes and Its Burden in the United States. Available from: www.cdc.gov/diabetes/pdfs/data/statistics/national-diabetesstatistics-report.pdf 
6. Ollberding NJ, Wolf RL, Contento I. Food Label Use and Its Relation to Dietary Intake among US Adults. J Am Diet Assoc. 2010;110:1233-7 Available from: http://ovidsp.ovid.com/ovidweb.cgi?T=JS\&PAGE= reference $\& D=$ med6\&NEWS=N\&AN=20656100\%0A http://ovidsp.ovid.com/ ovidweb.cgi?T=JS\&PAGE=reference\&D=emed12\&NEWS=N\&AN=359259090

7. Sharif MZ, Rizzo S, Prelip ML, Glik DC, Belin TR, Langellier BA, et al. The association between nutrition facts label utilization and comprehension among Latinos in two East Los Angeles neighborhoods. J Acad Nutr Diet. 2014;114:1915-22. https://doi.org/10.1016/j.jand.2014.05.004 Elsevier Inc.

8. Tolentino-Mayo L, Patiño SR, Bahena-Espina L, Ríos V, Barquera S. Conocimiento y uso del etiquetado nutrimental de alimentos y bebidas industrializados en México. Salud Publica Mex. 2018;60:328-37.

9. Haldeman L, Pérez-Escamilla R, Ferris AM, Drake L, Himmelgreen D, Bonello $H$, et al. Development of a color-coded bilingual food label for low-literacy Latino caretakers. J Nutr Educ Behav. 2000;32:152-60 Available from: http:// www.scopus.com/inward/record.url?eid=2-s2.0-0034178902\&partnerlD= 40\&md5=d582415a97adb12bfaaed7671ce4af8a.

10. Britigan DH, Murnan J, Rojas-Guyler L. A qualitative study examining Latino functional health literacy levels and sources of health information. J Community Health. 2009;34:222-30.

11. Tillotson JE. United States nutrition labeling and education act of 1990. Nutr Rev. 1991;49:273-6.

12. De la Cruz-Góngora $V$, Torres $P$, Contreras-Manzano A, Jáuregui de la Mota A, Mundo-Rosas V, Villalpando S, et al. Understanding and acceptability by Hispanic consumers of four front-of-pack food labels. Int J Behav Nutr Phys Act. 2017;14:28 Available from: http://ijbnpa.biomedcentral.com/articles/1 0.1186/s12966-017-0482-2.

13. The Strategic Counsel. Canadians' understanding and use of the nutrition facts table: baseline national survey results. 2011; POR 031-10(HCPOR-10-06).

14. Hobin E, Sacco J, Vanderlee L, White CM, Zuo F, Sheeshka J, et al. A randomized trial testing the efficacy of modifications to the nutrition facts table on comprehension and use of nutrition information by adolescents and young adults in Canada. Heal Promot Chronic Dis Prev Canada. 2015; 35:173-83 Available from: http://www.ncbi.nlm.nih.gov/pubmed/26674187.

15. Cecchini M, Warin L. Impact of food labelling systems on food choices and eating behaviours: a systematic review and meta-analysis of randomized studies. Obes Rev. 2016;17:201-10.

16. Campos S, Doxey J, Hammond D. Nutrition labels on pre-packaged foods: a systematic review. Public Health Nutr. 2011;14:1496-506.

17. Crockett RA, King SE, Marteau TM, Prevost AT, Bignardi G, Roberts NW, et al. Nutritional labelling for healthier food or non-alcoholic drink purchasing and consumption. Cochrane Database Syst Rev. 2018;27 Available from: http://doi.wiley.com/10.1002/14651858.CD009315.pub2.

18. Grieger JA, Johnson BJ, Wycherley TP, Golley RK. Evaluation of simulation models that estimate the effect of dietary strategies on nutritional intake: a systematic review. J Nutr. 2017;147:908-31 Available from: http://jn.nutrition. org/lookup/doi/10.3945/jn.116.245027.

19. Hodgkins CE, Raats MM, Fife-Schaw C, Peacock M, Gröppel-Klein A, Koenigstorfer J, et al. Guiding healthier food choice: systematic comparison of four front-of-pack labelling systems and their effect on judgements of product healthiness. Br J Nutr. 2015;1:1-12.

20. Arrúa A, MacHín L, Curutchet MR, Martínez J, Antúnez L, Alcaire F, et al. Warnings as a directive front-of-pack nutrition labelling scheme: comparison with the guideline daily amount and traffic-light systems. Public Health Nutr. 2017;20:2308-17.

21. Reyes M, Garmendia ML, Olivares S, Aqueveque C, Zacarías I, Corvalán C. Development of the Chilean front-of-package food warning label. BMC Public Health. 2019;19:906 Available from: https://bmcpublichealth. biomedcentral.com/articles/10.1186/s12889-019-7118-1.

22. Kelly $B$, Jewell J. Health evidence network synthesis report 61: what is the evidence on the policy specifications, development processes and effectiveness of existing front-of-pack food labelling policies in the WHO European region? World Heal Organ-WHO; 2018. p. 1-66.

23. Modelo de perfil de nutrientes de la Organización Panamericana de la Salud. Washington, DC: OPS, 2016.

24. Facts Up Front, 2011. Available online: http://www.factsupfront.org/ Newsroom/2, Accessed 29 Sept 2018

25. Diekman C, Levy M, Murray R, Stafford M, Kees J. A preliminary examination of facts up front: survey results from primary shoppers and at-risk segments. J Acad Nutr Diet. 2016;116:1530-6. https://doi.org/10.1016/j.jand.2016.01.007.
26. Roberto CA, Bragg MA, Schwartz MB, Seamans MJ, Musicus A, Novak N, et al. Facts up front versus traffic light food labels: a randomized controlled trial. Am J Prev Med. 2012:43:134-41.

27. Stern D, Tolentino L, Barquera S. Revisión del etiquetado frontal: análisis de las Guías Diarias de Alimentación (GDA) y su comprensión por estudiantes de nutrición en México. Inst Nac Salud Publica. 2013;53:37.

28. Food Standards Australia New Zealand. Guide for Industry to the Health Star Rating Calculator (HSRC). Canberra: Food Standards Australia New Zealand; 2015

29. Talati Z, Norman R, Pettigrew S, Neal B, Kelly B, Dixon H, et al. The impact of interpretive and reductive front-of-pack labels on food choice and willingness to pay. Int J Behav Nutr Phys Act. 2017;14:171.

30. Gorski Findling MT, Werth PM, Musicus AA, Bragg MA, Graham DJ, Elbel $B$, et al. Comparing five front-of-pack nutrition labels' influence on consumers' perceptions and purchase intentions. Prev med (Baltim) [internet] Elsevier. 2018;106:114-21. Available from. https://doi.org/10.1 016/j.ypmed.2017.10.022.

31. Grunert KG, Wills JM. A review of European research on consumer response to nutrition information on food labels. J Public Health (Bangkok). 2007;15:385-99.

32. Feunekes GIJ, Gortemaker IA, Willems AA, Lion R, van den Kommer M. Front-of-pack nutrition labelling: testing effectiveness of different nutrition labelling formats front-of-pack in four European countries. Appetite. 2008;50:57-70.

33. Grunert KG, Wills JM, Fernández-Celemín L. Nutrition knowledge, and use and understanding of nutrition information on food labels among consumers in the UK. Appetite. 2010;55:177-89.

34. Census Bureau. Overview of race and Hispanic origin: 2017. Available at: https://factfinder.census.gov/faces/tableservices/jsf/pages/productview. xhtml?pid=ACS_16_5YR_DP05\&src=pt. Accessed 13 July 2018.

35. US Census Bureau: Table QT-P10 Hispanic or Latino by Type. Archived. 2010: 2010 Available from: https:/factfinder.census.gov/faces/tableservices/jsf/ pages/productview.xhtml?pid=DEC_10_SF1_QTP10\&prodType=table.

36. Bleich SN, Wolfson JA. Differences in consumer use of food labels by weight loss strategies and demographic characteristics. BMC public health [internet]. BMC Public Health. 2015;15:1-8. Available from:. https://doi.org/1 0.1186/s12889-015-2651-z.

37. Pérez-escamilla $R$, Paso E. Place of residence modifies the association between acculturation and dietary tools knowledge among Latina WIC participants : a multi-state study. J Immigr Minor Health. 2012;13:299-308.

38. Guntzviller LM, King AJ, Jensen JD, Davis LSA. Self-efficacy, health literacy, and nutrition and exercise behaviors in a low-income. Hispanic Population J Immigr Minor Heal. 2017;19:489-93.

39. WHO. World Health Organization. Physical status: the use and interpretation of anthropometry. Report of a WHO Expert Committee. WHO Technical Report Series 854. Geneva, World Health Organization; 1995.

40. NORMA. Oficial Mexicana NOM-051-SCFI/SSA1-2010. Especificaciones generales de etiquetado para alimentos y bebidas no alcohólicas preenvasados-Información comercial y sanitaria. 2010:1-31 Available from: http://dof.gob.mx/nota_detalle.php?codigo=5137518\&fecha=05/04/2010.

41. Jensen JD, Ronit K. The EU pledge for responsible marketing of food and beverages to children: implementation in food companies. Eur J Clin Nutr. 2015;69:896-901.

42. Lobstein T, Landon J, Lincoln P. Misconceptions and misinformation: the problems with guideline daily amounts (GDAs) [internet]. National Heart Forum; 2007. Available from: http://nhfshare.heartforum.org.uk/RMAssets/ Reports/NHFGDAreport.pdf\%0A

43. Kaufer-Horwitz M, Tolentino-Mayo L, Jáuregui A, Bourges $H$, Kershenobich D, Rivera J, et al. Postura sobre un Sistema de Etiquetado frontal de Alimentos y Bebidas Para México: una Estrategia Para la Toma de Decisiones Saludables. Salud Publica Mex. 2018:479-86.

44. Sinclair S, Hammond D, Goodman S. Sociodemographic differences in the comprehension of nutritional labels on food products. J Nutr Educ Behav. 2013:45:767-72

45. Hersey JC, Wohlgenant KC, Arsenault JE, Kosa KM, Muth MK. Effects of frontof-package and shelf nutrition labeling systems on consumers. Nutr Rev. 2013;71:1-14.

46. Wartella EA, Lichtenstein AH, Allen LH, Crimmins J, Elbel B, Fox TA, et al. Front-of-Package Nutrition Rating Systems and Symbols: Promoting Healthier Choices. Inst. Med. Washington, DC: The National Academies Press; 2012. 
47. Freire $W B$, Waters WF, Rivas-Mariño G, Nguyen T, Rivas P, Krug EG, et al. A qualitative study of consumer perceptions and use of traffic light food labelling in Ecuador. Public Health Nutr. 2016;387:1-9.

48. Méjean C, Macouillard P, Péneau S, Hercberg S, Castetbon K. Perception of front-of-pack labels according to social characteristics, nutritional knowledge and food purchasing habits. Public Health Nutr [Internet]. 2013; 16:392-402 Available from: http://www.journals.cambridge.org/abstract_ S1368980012003515.

49. Fitzgerald N, Damio G, Segura-Pérez S, Pérez-Escamilla R. Nutrition knowledge, food label use, and food intake patterns among Latinas with and without type 2 diabetes. J Am Diet Assoc. 2008;108:960-7.

50. Khandpur N, de Morais SP, Mais LA, Bortoletto Martins AP, Spinillo CG, Garcia MT, et al. Are front-of-package warning labels more effective at communicating nutrition information than traffic-light labels? A randomized controlled experiment in a Brazilian sample. Nutrients. 2018:10:1-15.

51. Mejean C, Macouillard P, Péneau S, Hercberg S, Castetbon K. Consumer acceptability and understanding of front-of-pack nutrition labels. J Hum Nutr Diet. 2013;26:494-503.

52. Wojcicki JM. Heyman MB. Adolescent nutritional awareness and use of food labels : Results from the national nutrition health and examination survey. 2012:2-9.

53. Carter-Pokras O, Bethune L. Defining and measuring acculturation: a systematic review of public health studies with hispanic populations in the United States. A commentary on Thomson and Hoffman-Goetz. Soc Sci Med. 2009;69:992-5.

54. Wallace PM, Pomery EA, Latimer AE, Martinez JL. Salovey P. A review of acculturation measures and their utility in studies promoting Latino health. Hisp J Behav Sci. 2010:37-54.

55. Borgmeier I, Westenhoefer J. Impact of different food label formats on healthiness evaluation and food choice of consumers: a randomizedcontrolled study. BMC Public Health. 2009;9:184.

56. Grunert KG, Fernández-Celemín L, Wills JM, Bonsmann SSG, Nureeva L. Use and understanding of nutrition information on food labels in six European countries. J Public Health (Bangkok). 2010;18:261-77.

57. Gorton D, Ni Mhurchu C, Chen MH, Dixon R. Nutrition labels: a survey of use, understanding and preferences among ethnically diverse shoppers in New Zealand. Public Health Nutr. 2009;12:1359-65.

58. Hawley KL, Roberto CA, Bragg MA, Liu PJ, Schwartz MB, Brownell KD. The science on front-of-package food labels. Public Health Nutr. 2013;16:430-9.

59. Méjean C, Macouillard P, Péneau S, Lassale C, Hercberg S, Castetbon K. Association of perception of front-of-pack labels with dietary, lifestyle and health characteristics. PLoS One. 2014;9.

60. Davis RE, Johnson TP, Lee $\mathrm{S}$, Werner $\mathrm{C}$. Why do Latino survey respondents acquiesce? Respondent and Interviewer Characteristics as Determinants of Cultural Patterns of Acquiescence Among Latino Survey Respondents. Cross-Cultural Res. 2018;53:87-115.

61. Instituto Federal de las Comunicaciones. ADOPCIÓN DE LAS TIC Y USOS DE INTERNET EN MÉXICO [Internet]. 2016. Available from: http://www.ift.org.mx/ sites/default/files/contenidogeneral/estadisticas/ adopciondelasticyusosdeinternetenmexico.pdf

62. U.S. Department of Education, National Center for Education Statistics (2018). The condition of education 2018 (NCES 2018-144), Educationa Attainment of Young Adults.

63. Maukonen $\mathrm{M}, \mathrm{Männistö} \mathrm{S}$, Tolonen $\mathrm{H}$. A comparison of measured versus self-reported anthropometrics for assessing obesity in adults : a literature review; 2018.

64. Ortiz-panozo E, Yunes-díaz E, Lajous M, Romieu I, Monge A, Lópezridaura R. Validity of self-reported anthropometry in adult Mexican women, vol. 59; 2017

65. Cowburn G, Stockley L. Consumer understanding and use of nutrition labeling: a systematic review. Public Heal Nutr [Internet] 2005:8:21-28. Available from: http://www.journals.cambridge.org/abstract_S1368980005 000054

\section{Publisher's Note}

Springer Nature remains neutral with regard to jurisdictional claims in published maps and institutional affiliations.

\section{Ready to submit your research? Choose BMC and benefit from:}

- fast, convenient online submission

- thorough peer review by experienced researchers in your field

- rapid publication on acceptance

- support for research data, including large and complex data types

- gold Open Access which fosters wider collaboration and increased citations

- maximum visibility for your research: over $100 \mathrm{M}$ website views per year

At $\mathrm{BMC}$, research is always in progress.

Learn more biomedcentral.com/submissions 